\title{
A FORMAÇÃO INICIAL E A CAPACITAÇÃO DO PROFESSOR PARA ATUAR NA EDUCAÇÃO ESPECIAL
}

\author{
Leíta Dórea Tavares ${ }^{1}$ \\ Marcia Rebeca de Oliveira ${ }^{2}$
}

\begin{abstract}
Resumo
O presente artigo propõe uma discussão sobre a formação dos professores da Educação Especial destacando a importância da capacitação do referido profissional bem como a relevância da formação continuada em Educação Especial para o desenvolvimento da sua prática pedagógica. Para realizar este trabalho realizou-se um levantamento bibliográfico em livros, artigos científicos, acadêmicos e revistas cientificas. Conclui- se que os profissionais que atuam na Educação Especial necessitam de capacitação profissional para entender, discutir, aprender e aprimorar conhecimentos para atender os alunos que apresentam necessidades especifícas. Essa capacitação deve ser aprimorada em cursos de formação continuada que contribuam para avanços pessoais e profissionais de novas práticas pedagógicas e metodologias, para enriquecer a atuação com discentes que tenham alguma deficiência e/ou necessidades específicas a partir da consciência teórica e prática do processo inclusivo.
\end{abstract}

Palavras Chaves: Professor. Educação Especial. Capacitação. Formação Continuada.

\begin{abstract}
This article proposes a discussion on the training of Special Education teachers, highlighting the importance of training such professionals as well as the relevance of continuing education in Special Education for the development of their pedagogical practice. In order to carry out this work, a bibliographical survey was carried out on books, scientific, academic and scientific journals. It is concluded that professionals working in Special Education need professional training to understand, discuss, learn and improve knowledge to meet students who have specific needs. This training must be improved in continuing education courses that contribute to personal and professional advances in new pedagogical practices and methodologies, to enrich the performance with students who have some disability and / or specific needs based on the theoretical and practical awareness of the inclusive process.
\end{abstract}

Keywords: Teachers. Special Education. Training Continuing Education

\footnotetext{
${ }^{1}$ Mestra em Ciências da Educação pela Faculdade Interamericana de Ciências Sociais (FICS). Docente pela Secretaria Municipal de São Sebastião do Passé. Email: leitadores@yahoo.com.br

2 Doutoranda em Ciências da Educação pela Faculdade Interamericana de Ciências Sociais (FICS) Mestra em Ciências da Educação pela Faculdade Interamericana de Ciências Sociais (FICS). Especialista em Tecnologias Digitais Aplicadas a Educação (Uniasselvi). Especialista em Educação Inclusiva (IFEB). Especialista no Ensino de Libras(IFEB). Especialista em Comunicação Alternativa e Tecnologias Assistivas( SARTRE). Graduada em Licenciatura em Letras/Libras (UFSC). Docente do Instituto Federal da Bahia campus Valença. Coordenadora do Núcleo de Atendimento às Pessoas com Necessidades Específicas. Email: marciarebeca@ifba.edu.br
} 


\title{
Introdução
}

São muitos os desafios encontrados no processo de implantação da política de educação inclusiva no Brasil, mas a falta de preparo dos professores ganha destaque. A falta de qualificação dos professores da Educação Especial tem preocupado muito e não deixa de ser um desafio a ser vencido nas instituições de ensino para atender os alunos que apresentam alguma deficiencia e/ou necessidades específicas, pois:

\begin{abstract}
É preciso repensar a formação de professores especializados, a fim de que estes sejam capazes de trabalhar em diferentes situações e possam assumir um papel - chave. Deve ser adotada uma formação inicial não categorizada, abarcando todos os tipos de deficiência, antes de se enveredar por uma formação especializada numa ou em mais áreas relativas a deficiências específicas (BRASIL, 1994, p. 28). ${ }^{1}$
\end{abstract}

$O$ atendimento a esses educandos vem desafiando as escolas, e para tentar resolver esse problema, faz-se necessário o investimento na capacitação e formação continuada dos professores que atuam com esses discentes.

Nas escolas é comum encontrar, atuando na Educação Especial professores que não participaram de nenhuma formação para atender esses alunos, e outros que mesmo com formação encontram dificuldades em selecionar procedimentos de ensino e de apoio para compartilhar, confrontar e resolver conflitos cognitivos dos alunos com deficiência e/ou necessidades especificas. A capacitação de professores é uma das condições que assume centralidade na luta contra a exclusão educacional, conforme preconizam as Diretrizes Nacionais para a Educação Especial (BRASIL, 2001).

O educador da Educação Especial necessita ter conhecimentos teóricos e práticos bem como habilidades para organizar um planejamento pedagógico com objetivos, estratégias e atividades apropriadas para que esse aluno realmente tenha acesso ao conhecimento, ao diálogo e às diferentes formas de aprendizagens. Vale ressaltar a importância de inserir as atividades lúdicas no processo de ensino aprendizagem.

Ministrar aulas na Educação Especial é mais do que ter incluido um aluno com determinada deficiência em sala de aula, é necessário saber viabilizar, organizar, guiar e orientar as atividades deles durante o processo de aprendizagem para aquisição dos saberes e competências.

\footnotetext{
${ }^{1}$ De acordo com a Lei Brasileira de Inclusão, lei de número 13.146 de 06 de julho de 2015, o termo portador de deficiência, necessidades especiais ou necessidades educacionais especiais foi atualizado para Pessoa com Deficiência. O objetivo é analisar as possibilidades da pessoa/discente e não apenas suas limitações, possibilitando metodologias inclusivas adaptadas/flexibilizadas/adequadas.
} 
Diante dessa realidade os educadores são levados a repensar sua prática pedagógica e questionar sobre a eficiência de seus métodos, o que gera uma ansiedade em relação ao sucesso do processo de ensino-aprendizagem.

Para pensar em Educação Especial é necessário reconhecer a importância da capacitação e formação continuada do professor, que são dois aspectos intimamente ligados na promoção e criatividade da seleção de ferramentas pedagógicas que priorizem um melhor desempenho, beneficiando o desenvolvimento e a ampliação da competência discursiva, social, emocional,intelectual e cognitiva dos estudantes.

\section{A Importância da Capacitação Docente Para Atuação na Educação Especial}

Na Conferência Mundial sobre Educação para Todos em Jomtien, na Tailândia, em 1990 iniciaram-se os debates sobre a importância da formação de professores para trabalharem com alunos com dificuldades de aprendizagem.

Em 1994, surgiu a Declaração de Salamanca, expressando que "o planejamento educativo elaborado pelos governos deverá concentrar-se na educação para todas as pessoas em todas as regiões do país e em todas as condições econômicas, através de escolas públicas e privadas" (BRASIL,1994), e recomendando que a formação inicial devesse incutir em todos os professores uma orientação positiva, de forma que permitisse entender como as escolas poderiam conseguir avançar, utilizando os serviços locais de apoio e prol da inclusão com qualidade e equidade para esses discentes.

Sobre a formação de professores para trabalharem com alunos com deficiencia e/ou necessidades especificas, tanto a Conferência Mundial sobre Educação para Todos, quanto a Declaração de Salamanca abordam sobre as competências e habilidades que eram necessárias serem adquiridas, alertando que era necessário:

Os conhecimentos e aptidões requeridos em uma boa pedagogia, tais como: as capacidades de avaliar(..), de adaptar os conteúdos dos programas de estudos, de recorrer à ajuda da tecnologia, de individualizar os procedimentos pedagógicos e trabalhar em conjunto com especialistas e pais. (SILVA, 2016, p. 137).

São muitos os desafios encontrados na Educação Especial, mas a falta de preparo dos professores é relevante pois impacta diretamente na vida desses alunos que fazem parte das minorias. A falta de qualificação docente constitui-se como um desafio, visto que, os discentes que fazem parte da Educação Especial, segundo Mazzota (1982, p. 31), entre outras coisas : 
É bastante diversificada, uma vez que inclui uma grande variedade de alunos com necessidades das mais diversas. Essas necessidades, decorrem do confronto dos recursos educacionais comuns com as condições individuais de cada aluno. É a presença delas que vai, portanto, indicar se um aluno deve receber umaeducação especial, e não apenas a presença de uma deficiência ou superdotação, tomadas estas como condição individual .

Diante dessa realidade faz-se necessário discutir a preparação dos professores da Educação Especial no que se refere a prática pedagógica e questionar o conhecimento deste profissional sobre a eficiência dos métodos a serem usados para o sucesso do processo ensino e aprendizagem dos alunos com deficiência e ou necessidades específicas, pois:

\begin{abstract}
Para atuar na educação especial, o professor deve ter como base da sua formação, inicial e continuada, conhecimentos gerais para o exercício da docência e conhecimentos específicos da área. Essa formação possibilita a sua atuação no atendimento educacional especializado e deve aprofundar o caráter interativo e interdisciplinar da atuação nas salas comuns do ensino regular, nas salas de recursos, nos centros de atendimento educacional especializado, nos núcleos de acessibilidade das instituições de educação superior, nas classes hospitalares e nos ambientes domiciliares, para a oferta dos serviços e recursos de educação especial (BRASIL, 2008, p. 17)
\end{abstract}

O professor capacitado para trabalhar na Educação Especial, deve assumir o compromisso com a diversidade e com a equalização de oportunidades; trabalhar de forma interdisciplinar, privilegiar a colaboração e a cooperação; e precisa estar aberto para novos desafios e descobertas. A Educação Especial "está baseada na necessidade de proporcionar a igualdade de oportunidades, mediante a diversificação de serviços educacionais, de modo a atender às diferenças individuais dos alunos" (MAZZOTTA, 1982, p. 10).

O reconhecimento de dificuldades na formação docente para Educação Especial, não deve ser uma justificativa para os fracassos, mas sim um motor para a construção de experiências bem-sucedidas para uma educação de qualidade e verdadeiramente para todos.

A Lei de diretrizes e bases (LDB) de 1996 , ao definir o que os sistemas de ensino devem assegurar aos estudantes com deficiência, salienta a importância de "professores com especialização adequada em nível médio ou superior, para atendimento especializado, bem como professores do ensino regular, capacitados para a integração desses educandos nas classes comuns" (BRASIL, 2010, p. 44). 
Para oferecer uma educação de qualidade a esses educandos a escola precisa capacitar inicialmente e continuadamente seus professores para receber essas crianças e jovens, que são seres singulares e mesmo com a mesma deficiência ou necessidade específica necessita de uma metodologia direcionada e apropriada.

\section{A Relevância da Formação Continuada do Educador da Educação Especial}

A formação continuada do educador no contexto da Educação Especial visa à capacidade de reflexões dos acontecimentos e da trajetória das pessoas com deficiência, haja visto que analisa-se como era normal na antiguidade a eliminação dessas pessoas, pois naquela época acreditava-se que eles eram inúteis para a vida em sociedade.

É fundamental lembrar que só uma formação continuada comprometida com o bem de todos, fará a diferença na construção do conhecimento crítico, da autonomia dos alunos e da mediação da consciência dos mesmos. Esse público é feito de pessoas com personalidade única, que independente de estabelecerem uma boa comunicação com todos, são capazes de aprender cognitivamente e desenvolver múltiplas habilidades através de estímulos do meio, de atividades mediadas, diversificadas, apropriadas e flexibilizadas.

A formação continuada possibilita ao professor a atualização e a transformação de sua prática profissional. $O$ acesso ao conhecimento e o exercício da reflexão permitem a ressignificação dos princípios e a possibilidade de mudar os paradigmas já construídos.

Anteriormente acreditava-se que o professor, ao terminar sua formação inicial, estava preparado para a profissão pelo resto da vida. Freire (2001, p.64) diz que: "é na inconclusão do ser, que se sabe como tal, que se funda a educação como processo permanente." Esse educador mostra que a realidade é diferente para todos que atuam na escola, principalmente para o docente que deve conscientizar-se de que a formação é permanente no seu cotidiano.

A formação continuada é uma exigência da LDB 9394/96,os professores necessitam conhecer as leis que regem seus direitos e deveres, para que, assim, possam cobrar mais das autoridades competentes, sejam elas entidades públicas ou privadas (BRASIL, 1996). Entretanto, é importante destacar os deveres docentes no trabalho pedagógico com crianças que deve superar a dicotomia entre cuidar e educar, permitindo pelo processo da organização do tempo e do espaço, possibilidades para o conhecimento, para a aprendizagem e desenvolvimento. 
Segundo a LDB, o professor é extremamente relevante para que a qualidade do ensino seja cumprida e aperfeiçoada diariamente. Sua participação no dia a dia da escola, além da sala de aula, é primordial para seu crescimento pessoal e profissional, principalmente quando o item I ressalta sua participação na elaboração da proposta pedagógica da escola. Infelizmente muitas vezes o professor não consegue se dedicar como gostaria, em virtude da pressão diária no seu trabalho.

Apesar de toda a cobrança, os professores não podem permitir que a qualidade do ensino sofra,sendo preciso lutar para conseguir se estabelecer como um profissional capacitado e de qualidade. Freire (2001, p. 68) destaca que " não é parar de lutar mas, reconhecendo-se que a luta é uma categoria histórica, reinventar a forma também histórica de lutar", portanto o educador deve repensar a forma de luta que é necessária, para reerguer o lado profissional do professor, sendo importante, apesar de todas as dificuldades, continuar a ensinar com amor, dedicação, respeito, capacitação e de forma direcionada e apropriada para todos os seus alunos com ou sem deficiencia, prevalecendo a qualidade e empenho mesmo com dificuldades tão relevantes.

A formação continuada dos profissionais da educação representa uma das possibilidades de intervenção para um trabalho exitoso de um profissional, vale destacar que Michels,(2006) pontua que:

\begin{abstract}
A formação dos professores capacitados, tanto em nível médio como superior, deve ocorrer por meio de oferecimento de disciplinas, ou tópicos, que venham a contemplar as discussões sobre a educação de alunos considerados deficientes. Sua formação deve desenvolver competência para executar atividades e, ao mesmo tempo, aprender a trabalhar em equipe.
\end{abstract}

O professor que se empenha, que leva a sério a sua missão, enquanto educador e formador de opinião, consegue transformar sua sala de aula em um ambiente prazeroso e de boas descobertas, onde ele e os seus alunos embarcam todos os dias rumo a um novo conhecimento e uma educação inclusiva exitosa com equidade e qualidade.

\title{
Considerações Finais
}

O professor para atuar na Educação Especial precisa ter formação tanto em nível de graduação, (curso de Pedagogia), quanto na formação continuada para a construção de conceitos e aquisição de aprendizagem de ações pedagógicas que possam ser desenvolvidas na perspectiva da integração inclusiva social e profissional dos alunos com deficiência. 
O professor da Educação Especial em sua formação adquire conhecimentos, desenvolve habilidades, e preparo pedagógico para seleção de conteúdos e recursos metodológicos que possibilitem assegurar uma educação de qualidade a todos através de um currículo apropriado, arranjos organizacionais, estratégias de ensino e procedimentos pedagógicos pertinentes.

A formação continuada para o professor da Educação Especial se constitui na continuidade da aprendizagem de novos saberes para atender às novas demandas no ensino desse público alvo. Ela auxilia na capacidade de autonomia e no empenho dos professores de trabalhar na escola de forma significativa e clara, ou seja, tornar o seu aprendizado existente entrelaçado às situações corriqueiras para que elas sejam significativas possibilitando ao aluno além de manter-se em permanente atualização, considerar o ritmo acelerado do conhecimento humano em geral.

Buscar informações e aprender a selecioná-las são novas habilidades que o professor não pode deixar de desenvolver. Ser um eterno aprendiz, garante ao professor a possibilidade de colocar-se na posição de aprendente e, portanto, do aluno.

O profissional comprometido com o sucesso do processo de ensino e aprendizagem dos alunos com deficiência, deve rever constantemente a sua prática, tornando-se um sujeito ativo no processo de mudanças, buscando sempre a melhor forma de contribuir para a evolução e aprendizagem cognitiva, intelectual e social deles. Uma das formas da garantia do sucesso escolar, está ligado diretamente aa formação relevante e à interação dos profissionais que nela trabalham independente da função que exerce. Todos que fazem parte do setor pedagogico e que trabalham no ambiente educacional, devem ter o mesmo objetivo: formar cidadãos íntegros e conscientes de seus direitos e deveres na sociedade.

\section{Referênciais:}

BRASIL. Declaração de Salamanca e linha de ação sobre necessidades educativas especiais. Brasília - DF: CORDE, 1994.

BRASIL. Lei no 9394, de 20 de dezembro de 1996. Estabelece as Diretrizes e Bases da Educação Nacional. Diário Oficial da União, Brasília, 23 dez. 1996.

BRASIL. Diretrizes Nacionais para a Educação Especial na Educação Básica. Brasília: MEC/SEESP, 2001. 
BRASIL. Política nacional de educação especial na perspectiva inclusiva. Brasília, DF: MEC/SEESP, 2008.

BRASIL. Lei de Diretrizes e Bases da Educação Nacional: lei n. 9394/96. 5. ed. Brasília: Câmara dos Deputados, 2010.

FREIRE, P. Pedagogia da autonomia: Saberes necessários à prática educativa. São Paulo: Paz e Terra, 2001

Lei o 13.146, de 06 de julho de 2015. Institui a Lei Brasileira de Inclusão da Pessoa com Deficiência (Estatuto da Pessoa com Deficiência). Acesso em: 21 abr. 2019.

MAZZOTTA, M. J. S. Fundamentos de Educação Especial. São Paulo: Pioneira, 1982.

MICHELS, M.H. Gestão, formação docente e inclusão: eixos da reforma educacional brasileira que atribuem contornos à organização escolar. Rio de Janeiro: Revista Brasileira de Educação, 2006

SILVA, J. M. E. et al. Capacitação docente, educação inclusiva e educação especial. Teófilo Otoni: Revista Multidisciplinar do Nordeste Mineiro, 2016 